\title{
Rational therapy of chronic venous insufficiency - chances and limits of the therapeutic use of horse-chestnut seeds extract Bertram Ottillinger ${ }^{* 1}$ and Karin Greeske ${ }^{2}$
}

Address: ${ }^{1}$ Foehrenstrasse 12, 85649 Hofolding, Germany and ${ }^{2}$ Klinge Pharma GmbH, Berg-am-Laim-Strasse 129, 81673 Munich, Germany E-mail: Bertram Ottillinger* - bertram.ottillinger@vicron.net; Karin Greeske - karin.greeske@klinge-pharma.de *Corresponding author

Published: 7 December 200I

BMC Cardiovascular Disorders 200 I, I:5

This article is available from: http://www.biomedcentral.com/I47I-226I/I/5

(C) 200I Ottillinger and Greeske; licensee BioMed Central Ltd. Verbatim copying and redistribution of this article are permitted in any medium for any non-commercial purpose, provided this notice is preserved along with the article's original URL. For commercial use, contact info@biomedcentral.com
Received: |4 September 200I

Accepted: 7 December 200I

\begin{abstract}
Background and methods: We report two clinical studies, one already published, performed in patients with early and advanced chronic venous insufficiency (CVI). In both, compression therapy and oral therapy with horse-chestnut seeds extracts (HCSE) were compared to placebo.
\end{abstract}

Results: The published study in early CVI (Grade I) showed HCSE and compression to be superior to placebo and to be equivalent to each other in reducing lower leg volume, a measure for oedema.

In the study, in advanced CVI (Grade II and IIla), compression appeared to be superior to placebo, whereas HCSE was not. HCSE fared better in Grade II than in Grade Illa patients.

These results are discussed in the light of data from an in vitro model, where HCSE has been able to close the intercellular gaps in the venular endothelium. Not fully specified factors lead to an opening of these gaps, resulting in oedema as well as in local coagulation and thrombosis. The subsequent inflammation keeps these gaps open and initiates and maintains a chronic disease process, which may be the starting point of CVI.

Conclusion: Due to its ability to close the venular endothelial gaps, HCSE seems to be a suitable and protecting therapy during the early stages of CVI. In later more severe stages compression therapy is indicated. Taking into account the observed negative impact of compression on quality of life, pharmacological CVI therapy should start early to avoid progress and to spare patients compression therapy.

\section{Introduction}

Chronic venous insufficiency (CVI) is a common disease; approx. 25\% of the Western European population suffer from it. CVI is no minor disorder; because of its chronic character patients require long-term treatment, often in hospital or sanatorium, including surgical intervention. In the end symptoms often force them to retire prematurely, with severe personal and social restrictions [1-4]. In Germany alone, the economical damage caused by
CVI is estimated at several billion Mark per year [5]. Frequently CVI is still regarded a physical or mechanical disorder. Varicosis, thrombosis, and/or increased haemostatic pressure following standing or sitting over long periods lead to insufficiently closing venous valves. This results in haemodynamic alterations and a reduced, or even reversed, venous blood flow. The reduced drainage of venous blood and peripheral venous hypertension lead to chronic hypoxia of the surrounding tissues, espe- 


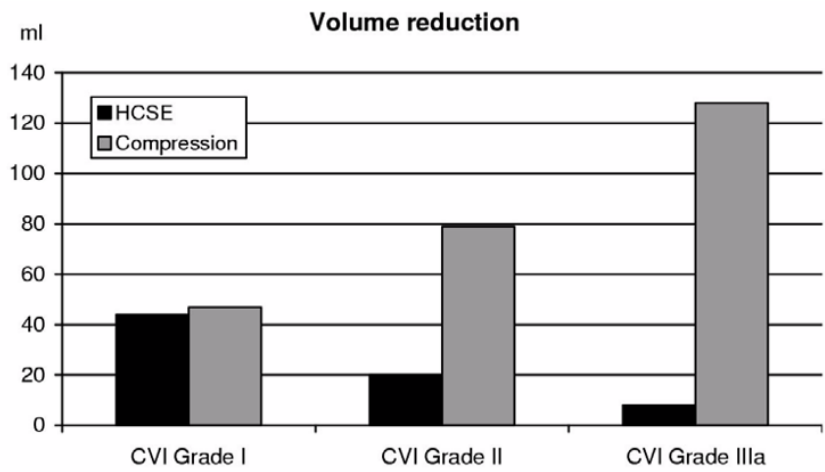

Figure I

Lower leg volume reduction - relation of CVI grade and form of therapy.

cially of the venous wall itself. Oedemas, the first symptom when venous blood flow decompensates, inhibit microcirculation. They lead, in the course of the disease, to inflammatory reactions of the hypodermis, followed by the characteristic signs of stasis-induced dermatitis like sclerosis and atrophia. End stage of the disease are badly healing crural ulcers. The focus of classical therapy are larger veins as the putative origin of venous disease, with compression therapy as the gold standard [6].

Because of their anti-inflammatory, anti-oedematous, and venotonic properties, horse-chestnut extracts (HCE) or horse-chestnut seeds extracts (HCSE), standardised to aescin, have been studied extensively in preclinical models of CVI and in patients with the disease. A comprehensive overview of the current knowledge on aescin has been compiled by Sirtori; the review includes extensive data on the mechanism of action and on the clinical properties of the drug [7].

We report seemingly conflicting clinical data from two studies with HCSE in patients with CVI. Both studies were performed to compare the efficacy of HCSE with that of compression therapy on the reduction of lower leg volume. The studies had a similar design and included a placebo control. The results of one study have been reported previously [8].

\section{Clinical study \# I \\ Patients and methodology}

The first multicentre study [8] included patients predominantly with CVI Grade I according to the classification of Widmer and Marshall [9,10 ${ }^{1}$ (See Competing Interests). Following an a priori created random list, patients were randomised into a placebo group, a compression group, and a group receiving one capsule of HCSE, standardised to $50 \mathrm{mg}$ aescin, twice daily (Venostasin ${ }^{\circledR}$ retard, Klinge Pharma, Munich, Germany). The patients of the compression group received a diuretic (25 $\mathrm{mg}$ hydrochlorothiazide/50 mg triamterene) once daily during the first treatment week to enable the application of optimum fitting stockings.

The study was double-blind regarding allocation to HCSE or placebo and open regarding allocation to the compression group. The treatment phase of 12 weeks was preceded by a 2-week placebo run-in phase.

The main efficacy parameter was change of lower leg volume, determined by water replacement plethysmometry. Lower leg volume was determined at baseline and after 4,8 , and 12 weeks of therapy.

\section{Results}

Of the 240 patients recruited, the compression group comprised 99 patients, the HCSE group 95 patients, and the placebo group 46 patients.

In the placebo group lower leg volume increased slightly ( $9 \pm 11 \mathrm{ml}$; mean \pm standard error of the mean) during the first four weeks of therapy and remained at that level until study end (10 $\pm 15 \mathrm{ml})$. The patients of the compression group experienced a quick and large improvement ( $45 \pm 8 \mathrm{ml}$ ) during the first month of therapy, which was probably influenced by the use of the diuretic during the first week of the study. This improvement was maintained until study end ( $47 \pm 8 \mathrm{ml})$. In the HCSE group lower leg volume decreased continually $(17 \pm 9 \mathrm{ml}$ at week $4,27 \pm 10 \mathrm{ml}$ at week 8 ) and reached practically the same volume reduction as the compression group at the final examination ( $44 \pm 11 \mathrm{ml}$; see Figure 1, left columns). The differences between placebo and the two active treatment groups were significant (compression: $\mathrm{p}=$ o.002; HCSE: $\mathrm{p}=0.005$ ). Also the test on equivalence/ non-relevant inferiority of HCSE vs. compression therapy was significant $(\mathrm{p}=0.001)$.

The patients in the compression group showed significantly worse quality of life scores than HCSE patients in the parameters "reduction of well-being", "limitation of normal daily activities", "limitation of working ability", "limitation of leisure activities", and "limitation of enjoyment of life". Compression generally was even (non-significantly) worse than placebo in these parameters.

In this study, the incidence of adverse events or adverse drug reactions between treatment groups was not significantly different. No serious adverse drug reactions appeared. Adverse drug reactions of the gastrointestinal tract were somewhat more frequent in the HCSE group ( 5 events of nausea, heartburn, or fullness in 4 patients = 
$4 \%$ ) than in the compression group (2 events of nausea in 2 patients $=2 \%$ ).

\section{Clinical study \#2 \\ Patients and methodology}

A second randomised, multicentre study included patients with CVI Grade II and Grade IIIa [C Diehm, C Schmidt. Venostasin ${ }^{\circledR}$ retard gegen Plazebo und Kompression bei Patienten mit CVI II/IIIA. Final Study Report. Klinge Pharma GmbH, Munich, Germany. 21 November 2000]. Patients who had received therapy with vein drugs during the preceding 6 weeks and patients with oedemas of non-venous origin were excluded.

Also in this study, an a priori created random list randomised patients blockwise to HCSE therapy (50 mg aescin twice daily, Venostasin ${ }^{\circledR}$ retard, Klinge Pharma, Munich, Germany), to compression therapy after a one week course of diuretic, and to placebo. The study was double-blind regarding allocation to HCSE or placebo and open regarding allocation to the compression group.

The therapy phase was preceded by a two-week placebo wash-out. Treatment lasted for 16 weeks. A 2-week follow-up period after the treatment phase allowed an estimate whether treatment effects were maintained.

Lower leg volume was determined by plethysmometry at baseline, at weeks $4,8,12$, and 16 of therapy, and twice during the follow-up period. Main efficacy criterion was the reduction of lower leg volume between start of therapy (Week o) and end of therapy (Week 16). An a priori ordered set of hypotheses (comparison of HCSE to placebo - comparison of compression to placebo - comparison of HCSE to compression) was tested with modified Utests at an $\alpha$-level of 0.05 .

One secondary efficacy criterion was a subjective symptoms score computed from the symptoms heaviness, distension, distension pain, feeling of swelling, tiredness in the leg, itching, leg cramps, paraesthesia, plantar burning, and unspecific subjective complaints (range from $10=$ healthy to $50=$ maximum expression of symptoms).

Quality of Life served as a further secondary parameter. It was determined using the "Fragebogen zur Lebensqualität bei Venenerkrankungen" FLQA, developed by the Dermatological University Hospital of the AlbertLudwigs-University in Freiburg, Germany.

The sample size calculation assumed a standardised leg volume difference of 0.5 between HCSE and placebo and a standardised difference of 0.35 as the equivalence range for the comparison of HCSE and compression. This resulted in a total required patient number of 350
(140 each for the active treatment groups and 70 for the placebo group).

\section{Results}

355 patients were included in this study. The compression group comprised 142 patients, the HCSE group 143 patients, and the placebo group 70 patients. Most patients suffered from CVI Grade II $(n=284)$, fewer from CVI Grade IIIa $(n=71)$. No relevant inhomogeneities between treatment groups were seen.

Both active therapy groups showed a monotonous reduction of lower leg volume during the treatment phase, whereas the placebo group did not.

Mean decrease ( \pm standard deviation) from start to end of therapy was $89 \pm 122 \mathrm{ml}$ in the compression group and $18 \pm 75 \mathrm{ml}$ in the HCSE group. The placebo patients showed a mean increase of lower leg volume of $2 \pm 82 \mathrm{ml}$. After the end of therapy, i.e. during the two-week followup phase, an increase in lower leg volume was observed, more in the compression group $(50 \mathrm{ml}=56 \%$ of improvement at Week 16) than in the HCSE group $(8 \mathrm{ml}=$ $44 \%$ of improvement at Week 16). In the compression and in the HCSE groups, volumes at the end of the study were still considerably below the starting values, indicating some persistence of effects. The placebo group had exactly reached its starting point again.

Compression was significantly superior to placebo ( $\mathrm{p}<$ o.oo1), whereas HCSE was not $(p=0.115)$. Only in the per-protocol population, consisting of 286 patients, HCSE also demonstrated a significant superiority to placebo $(p=0.018)$.

The subjective symptoms evaluation at study end favoured HCSE over compression. The difference, however, did not reach statistical significance (reduction of total symptom score for compression: $4.56 \pm 5.77$; for HCSE: $4.94 \pm 6.82$; higher numbers indicate superiority).

As in the study reported above [8], also here HCSE showed more favourable results than compression in the quality of life parameters. Compression was worst of the three treatment groups in four of seven subscales and best in only one. HCSE, on the other hand, was best in three of the subscales. A complete statistical evaluation of this secondary endpoint was not performed.

A subgroup analysis of CVI grades showed that Grade II patients better responded to HCSE than Grade IIIa patients (volume reduction: $20 \pm 77 \mathrm{ml}$ vs. $8 \pm 63 \mathrm{ml}$; see Figure 1, middle and right columns). Compression, on 
the other hand, was more effective in the higher CVI grade (volume reduction: $128 \pm 132 \mathrm{ml}$ vs. $79 \pm 119 \mathrm{ml}$ ).

The incidence of adverse events between the groups in this study was not significantly different. Gastrointestinal adverse events were more frequent in the HCSE group ( $15 \%$ of patients affected) than in the compression (7\%) or in the placebo group ( $9 \% ; \mathrm{p}=0.09$; $\mathrm{Chi}^{2}$ test). These were practically exclusively cases of gastroenteritis, heartburn, nausea, vomiting, diarrhoea, and abdominal pain or cramps. Two cases of constipation and three cases of dry mouth occurred solely in the HCSE group. Absolute incidence of adverse events seems higher than in Study \#1, but is caused by non-related adverse events; these cases were excluded from the calculation of incidence in Study \#1. No serious adverse drug reactions occurred.

\section{Discussion}

Other than Study \#1, Study \# 2 could not prove the equivalence of HCSE and compression in patients with CVI. We assume that this is related to differences in patient populations. Whereas Study \#1 included patients in the very early stages of CVI (Grade I), patients with advanced CVI were recruited (Grades II and IIIa) for Study \#2. Lower CVI grades seem to be more suitable for therapy with HCSE. Figure 1 combines the results from both studies and illustrates these findings.

When interpreted in the light of a recent publication by Nees et al. [11], theses findings become plausible. Nees focuses on the role of the smaller vessels and their endothelium, as opposed to the venous valves, as the starting point for CVI.

The venular endothelium possesses a unique property, which gives it a specific role in the development of CVI. It is, unlike the endothelium of other vessels, a contractile tissue actively regulating the width of its intercellular gaps. Especially inflammatory mediators open these gaps $[11,12]$.

Opening of the venular gaps leads to an outflow of blood and plasma components to the surrounding interstitial tissues and forms the microscopic correlate to the oedema observed clinically. Thrombogenic factors, e.g. tissue factors, induce interstitial inflammation and thrombosis, which spread to the venular lumen, possibly via the open gaps, reducing or cutting off perfusion. This inflammation may maintain the opening of the venular gaps, thus resulting in a circulus vitiosus, a chronic situation. Thrombocytes, polymorphonuclear granulocytes, Tlymphocytes, and monocytes are attracted to the site of inflammation and secrete aggressive oxidative or hydrolytic enzymes. Due to the reduced blood flow and damage in the venular endothelium they are insufficiently diluted [11].

This scenario may also occur in the vasa venorum, i.e. the supply vessels of the larger veins [13]. This is especially relevant for the promotion to the later stages of CVI. Microthrombi and inflammation of the venules, in the direct neighbourhood of the larger veins, may compromise the normal metabolism of venous wall structures, e.g. of the venous valves, eventually leading to their destruction. Histological evaluation of veins from later stages of CVI supports this hypothesis $[14,15]$.

It remains still unclear which factors lead to an opening of the venular gaps in the first place. Hypotheses include immunological attacks of unknown origin, hypoxia, nutritive or toxic causes, infections, and acquired or genetic metabolic factors $[7,11,16]$.

In an attempt to find causative forms of therapy for CVI, Nees et al. evaluated the influence of horse-chestnut seeds extracts (HCSE) on the contractility of the venular endothelial cells [11]. They examined the permeability of guinea pig venular endothelium to water applied under pressure (hydraulic conductivity). Application of polymorphonuclear granulocytes and activated thrombocytes to the endothelial cells increased their hydraulic conductivity by a factor of approximately $15 \mathrm{vs.} \mathrm{control.}$ This reflected the opening of the endothelial gaps, which could also be observed directly by scanning electron microscopy.

The parallel addition of HCSE inhibited the increase in conductivity in a dose dependant manner and almost completely in a concentration of 0.01 or $0.1 \mathrm{mg} / \mathrm{ml}$ (depending on extract used). The addition of the extracts, ten minutes after the polymorphonuclear granulocytes and thrombocytes, even restituted the increased conductivity almost to baseline values. These effects were observed and verified also by scanning electron microscopy. These findings were replicable also in human venular endothelium [Nees, personal communication].

HCSE required the presence of and probably the binding to serum proteins to show an effect (serum proteins alone did not show any effect and were used as a negative control). Possibly serum concentrations of free HCSE in man do not correspond to therapeutic efficacy [11].

\section{Conclusion}

We conclude that in early stages of CVI, when the veins and their wall structures have not yet suffered any permanent damage, pharmacological methods may be sufficient to interact with the disease process. Closure of the 
venular endothelial gaps interrupts the circulus vitiosus. If venules and surrounding tissues have not yet been permanently damaged they have a chance to regenerate.

Also in the later stages of CVI, HCSE may still close the venular endothelial gaps and thus can reduce oedema to some extent, as shown in Study \#2 (Figure 1). At this time, however, the disease process has already involved the larger veins, with irreversible damage.

Adequate therapy in this stage of CVI is compression. It increases blood velocity by mechanically reducing the cross-section of the larger veins. Additionally the increased perivascular pressure inhibits the outflow of blood and plasma factors from the endothelial venular gaps, which reduces contact with tissue factor and thus the initial steps of coagulation and thrombosis $[11,17,18]$.

Nevertheless compression cannot restitute destroyed venous structures, but remains a mainly symptomatic therapy. Especially when taking into account the reduced quality of life under compression therapy, patients in the early stages of CVI should be offered pharmacological treatment rather than to wait until the only help is compression.

\section{Competing interests}

Dr. Ottillinger is an independent consultant for the medical and pharmaceutical industry. He has received honoraria for the preparation of this manuscript.

Dr. Greeske is an employee of Klinge Pharma GmbH, a company which markets a product containing a horsechestnut seeds extract.

1 (See Competing Intrests) Grade I: Lateral phlebectasia of the feet (corona phlebectatica paraplantaris) and tendency for oedema

Grade II: Additionally different forms of trophic dermatosis like hyperpigmentation, hyperkeratosis, dermatosclerosis

Grade IIIa: Healed crural ulcer

Grade IIIb: Non-healed crural ulcer

\section{References}

I. Berg D, Beck M, Jesau R: Venenerkrankungen und Bevölkerungsstruktur. Vasa I99I, Suppl. 33:256

2. Biland L, Widmer LK: Varicose Veins (VV) and Chronic Venous Insufficiency (CVI). Acta Chir Scand I 988, Suppl 544:9-I I

3. Diehm C: Epidemiologie und Pathogenese der Varikosis. Herz 1989, 14:267-273

4. Marshall M: Sozialmedizinische Bedeutung, Kosten, Verlauf, Therapie und Prognose der Venenerkrankungen. Versicherungsmedizin 1989, 41:89-97
5. Schäfer P: Kompressionstherapie der Venenleiden. Pharm Ztg 1994, 3: I 36- 145

6. Partsch H: Compression therapy of the legs. J Dermatol Surg Oncol | 99|, | 7:799-805

7. Sirtori CR: Aescin: Pharmacology, Pharmacokinetics and Therapeutic Profile. Pharmacol Res 200 I, 44(3):183-193

8. Diehm C, Trampisch HJ, Lange S, Schmidt C: Comparison of leg compression stocking and oral horse-chestnut seed extract therapy in patients with chronic venous insufficiency. Lancet 1996, 347(8997):292-294

9. Widmer LK, Stähelin HB, Nissen C, da Silva A: Venen-, ArterienKrankheiten, koronare Herzkrankheit bei Berufstätigen. Verlag Hans Huber, Bern, Stuttgart, Wien I98I

10. Marshall M: Diagnostik der Venenerkrankungen - Teil I. Herz Kreislauf 1994, 26:211-218

11. Nees S, Weiss D, Thallmair P, Lamm P, Juchem G: Neue Aspekte zur Pathogenese und Therapie chronisch peripherer Venenleiden. Fortschritt und Fortbildung in der Medizin 200I, 24: I-20

12. Grega GJ, Adamski SW: The role of venular endothelial cells in the regulation of macromolecular permeability. Microcirc Endothelium Lymphatics 1988, 4:143-167

13. Alexander RS: The peripheral venous system. In: WF Hamilton, $P$ Dow (eds.): Handbook of Physiology. Section 2: Circulation. Vol. I I: I075II 33. American Physiological Society, Washington DC 1963

14. Kockx MM, Knaapen MW, Bortier HE, Cromheeke KM, BoutherinFalson $\mathrm{O}$, Finet $\mathrm{M}$ : Vascular remodeling in varicose veins. Angiology 1998, 49:87|-877

15. Kirsch D, Schreiber J, Dienes HP, Böttger Th, Junginger Th: Alterations of the extracellular matrix of venous walls in varicose veins. VASA 1999, 28:95-99

16. Arnould T, Janssens D, Michiels C, Remacle J: Effect of asecin on hypoxia-induced activation of endothelial cells. Eur J Pharmacol 1996, 3 I 5(2):227-233

17. Ernst $E$, Saradeth $\mathrm{T}$ : Konservative Therapie der chronisch venösen Insuffizienz. Wien Klin Wochenschr 1992, 1:16-22

18. Lofferer O, Mostbeck A, Partsch H: Die Kompressionsbehandlung bei venösen und lymphatischen Abflußstörungen der Beine. Acta Med Austriaca 1976, 4:138-142

Publish with BioMed Central and every scientist can read your work free of charge

"BioMedcentral will be the most significant development for disseminating the results of biomedical research in our lifetime." Paul Nurse, Director-General, Imperial Cancer Research Fund

Publish with BMC and your research papers will be:

- available free of charge to the entire biomedical community

- peer reviewed and published immediately upon acceptance

- cited in PubMed and archived on PubMed Central

- yours - you keep the copyright

Submit your manuscript here: BioMedcentral.com http://www.biomedcentral.com/manuscript/ editorial@biomedcentral.com 